Case Report

\title{
Delayed Puberty in Girls with Primary Amenorrhea: A Report of Cases
}

\author{
Fatinah Shahab $^{1,2}$, Inu Mulyantoro ${ }^{2,3}$, Hary Tjahjanto ${ }^{2,3}$, Tri Indah Winarni ${ }^{2,4}$, Sultana Faradz ${ }^{*}$ \\ ${ }^{1}$ Faculty of Medicine, Wahid Hasyim University, Semarang, Indonesia. \\ ${ }^{2}$ Faculty of Medicine, Universitas Diponegoro, Semarang, Indonesia \\ ${ }^{3}$ Dr. Kariadi General Hospital, Semarang, Indonesia \\ ${ }^{4}$ Center for Biomedical Research, Faculty of Medicine, Universitas Diponegoro, Semarang, Indonesia
}

\section{Article Info}

History

Received: 15 Aug 2021

Accepted: 31 Aug 2021

Available: 31 Aug 2021

\begin{abstract}
Background: Female puberty starts when the pituitary hormone producing folliclestimulating hormone (FSH) and luteinizing hormone ( $\mathrm{LH})$, which will stimulate the ovaries to produce estrogen. Delayed puberty with primary amenorrhea in female is the lack of breast development followed by the absence of menses 3 years after the initiation of breast development. Sex chromosomes have an important role in determining the sex, germ cell differentiation of foetus, and reproductive functions of an offspring, thus, sex chromosomal aberrations frequently cause primary amenorrhea Case presentation: We report two delayed puberty cases with the chief complain of primary amenorrhea. Both cases showed hypoplasia of uterus and ovaries on pelvic imaging and hormonal assay showed low of FSH. The first case was gonadal dysgenesis with 46,XX karyotype and low level of estrogen and the second case was a turner syndrome with 45,X karyotype and normal level of estrogen.

Conclusion: This study reported delayed puberty with primary amenorrhea cases due to different chromosomal aberration pattern which have similar clinical features. Therefore, cytogenetic examination is needed for any primary amenorrhea cases in order to accomplish the confirmatory diagnosis and make a correct intervention and treatment.
\end{abstract}

Keywords: Delayed Puberty; Primary Amenorrhea; Cytogenetic. Permalink/ DOI: https://doi.org/10.14710/jbtr.v7i2.12054

\section{INTRODUCTION}

Transition period from childhood to adulthood called puberty is a maturational process of reproductive endocrine system resulting in the achievement of adult height, body proportion, genital organ development, and reproductive capacity. It is characterized by acquisition of secondary sexual characteristics that is the transition of breast, pubic and axillary hair described using maturity ratings such as Tanner stages from stage 1 to stage 5 and menarche is a late marker of puberty. ${ }^{1}$ In female, puberty was began when the pituitary hormone releasing follicle-stimulating hormone (FSH) and luteinizing hormone $(\mathrm{LH})$ that energizing the granulosa cells of the ovarian follicles and corpora luteum to produce estrogen. $^{2}$

\footnotetext{
* Corresponding author:

E-mail: sultanafaradz@gmail.com

(Sultana MH Faradz)
}

The onset of puberty is characterized by the transition from Tanner breast stage B1 to B2, and growth spurt starts shortly after breasts begin to develop, called thelarche. Menarche, the event of a first menstrual period in a female adolescent resulting of a matured hypothalamic-pituitary-ovarian (HPO) axis, and it usually begin 2-3 years after thelarche. ${ }^{3}$ Timing of puberty is strongly controlled by genetic regulation, epidemiological study estimated of $50-80 \%$ of variation is driven by genetic. ${ }^{1,4}$ The advancement of puberty, that is, the rate of which an individual will accomplish fecundity (reproductive performance), fertility, and absolute maturation, was determined by genetic. ${ }^{5}$ Beside, environmental factors also play an important role in regulating puberty and pubertal progression includes cultural, nutrition, psychological, and endocrine disruptor chemicals. ${ }^{3,} 6$ Several pathological states influence the timing of puberty either directly or indirectly. ${ }^{3}$ 
Delayed puberty (DP) is defined as the absence of physical signs of puberty by age of 14 years in boys and 13 years in girls, affecting $2 \%$ of the adolescent population and is usually associated with adverse health problems such as short stature and reduced bone mineral density. ${ }^{7} \mathrm{DP}$ is a common concern for patients, parents, family, and peers and a common reason of paediatric and obstetric endocrine consultation, it is often a self-limited which generally spontaneously reaches completion by 18 years of age. Self-limited DP is found in two third of boys and in nearly half of girls. ${ }^{8}$ DP which occurs constitutionally, called constitutional delay of growth and puberty (CDGP), characterized by growth retardation in childhood and delayed puberty in adolescence is strongly associated with genetic component, have a family history of DP. ${ }^{9}$ There are two pathophysiological background of DP 1.e; hypergonadotropic hypogonadism and central hypogonadotropic hypogonadism. Hypergonadotropic hypogonadism affects especially in female and Turner syndrome is the most case of this type, while, central hypogonadotropic hypogonadism or functional hypogonadism is mostly due to a chronic disease and nutritional or stressing factors that able to inhibit the activation of the hypothalamic-pituitary-gonadal (HPG) axis, corresponding to approximately in $20 \%$ of DP. ${ }^{8}$ The aetiology is unknown in the majority of DP patients and identification of causal genetic defects in familial delayed puberty is complex. HPG axis is inactive until the beginning of puberty, characterized by a gradual increase in hypothalamic gonadotropin-releasing hormone secretion that will stimulate the secretion of FSH and LH. ${ }^{1}$

Disorder of sex development (DSD) is a condition of atypical chromosomal, gonadal or sexual characteristics resulting of urogenital tract development and varied clinical phenotype. ${ }^{10}$ It mostly impacted on gonadal function and by that means the puberty-menarche, thus the pubertal development may be absent or incomplete.

Primary amenorrhea (PA) is defined as lack of menarche or absence of menstruation in females of reproductive by age 16 when the development of secondary sexual characteristic is evident (breast development, pubic hair) or by age 14 when there are no secondary sexual characteristics are present. ${ }^{11} \mathrm{PA}$ is one of the most common reasons of obstetric-gynaecologic consultation in adolescent girls. The primary amenorrhea is categorized into functional or anatomic defect of hypothalamus, pituitary, uterus or ovaries, and genetic defect at chromosomal or molecular level. Sex chromosomal aberration is the etiological cause of primary amenorrhea in almost $25 \%$ of cases. ${ }^{12,13}$ When pubertal development was delayed, a full physical examination is needed to consider broad spectrum of differential diagnosis. ${ }^{1}$ Cytogenetic investigations have shown a variety of chromosomal abnormalities as a major cause of amenorrhea. ${ }^{14}$

Some girls with delayed puberty may have problems with their ovaries, either not developing properly or are being damaged. This is referred to as primary ovarian insufficiency (POI) due to the lack of LH and FSH. Most girls with Turner syndrome are extremely short for their age and may have certain distinctive physical features, such as cubitus valgus, low posterior hairline, webbed neck. Hypogonadotropic hypogonadism affects female with hypothalamus and pituitary are functioning appropriately but have the gonadal failure. ${ }^{15}$ Female gonadal dysgenesis is defined as absence or insufficient development of ovaries present with delayed puberty and primary amenorrhea. ${ }^{16}$

This study reported two cases patient with DP and PA who had different chromosomal aberrations in order to convince the important of chromosomal evaluation to confirm the diagnosis/aetiology and to assure an appropriate treatment.

\section{CASE REPORT}

Two serial cases were referred to our hospital with delayed pubertal and primary amenorrhea.

\section{Case 1}

An 18-year-old female (III.7) was referred to our hospital for delayed puberty and primary amenorrhea. Her pubertal status was Tanner I for breast, axilla and pubic hair development. Her growth chart was notable for a delayed growth spurt. Her weight and height were 26 $\mathrm{kg} 143 \mathrm{~cm}$ respectively with her BMI $12.7 \mathrm{~kg} / \mathrm{m}^{2}$. The mother states that she still had used intra uterine device (IUD) until two weeks of pregnancy and she was taking an oral medicine for adequate uterine prescribed by obstetrician. The mother took oral medication due to psoriasis on her early pregnancy and used topical corticosteroid during pregnancy, but forgot type of corticosteroid treatment she had. The mother also reported that she did hair coloring which containing organic and mineral chemicals every month during pregnancy. She delivered normally at 7 months of gestational age and assisted by midwife. Her birth weight was $2 \mathrm{~kg}$ and birth length $43 \mathrm{~cm}$. The patient taking medications for almost 11 months due to tuberculosis at 6 year of age and never check for recovery after treatment. She had no abdominal pain, headache, visual disturbances, acne or hirsutism. There was no family history with the same condition (Figure 1). She had hyperactive behavior during childhood and learning difficulties. Pubertal timing of the mother and grandmother was normal. There was no consanguinity in this family. On physical examination there was a vaginalintroital opening. Pubertal assessment reveals Tanner stage I of Breast development, pubic hair and axillary hair. The external genitalia were completely female. (Figure 2)

Table 1. Laboratory evaluations of Case 1

\begin{tabular}{lll}
\hline Hormone & Result & Reference range \\
\hline FSH $(\mathrm{mI} / \mathrm{ml})$ & 0.96 & $\begin{array}{l}\text { Follicular phase : 3.03-8.08 } \\
\text { Mid-cycle peak : 2.55-16.69 } \\
\text { Luteal phase : 1.38-5.47 }\end{array}$ \\
& & Post menopause females without \\
& & HRT : 26.72-133.41 \\
& & $2-29$ \\
Prolaktin & 5.46 & \\
$($ ng/mL $)$ & & Follicular phase: $18-147$ \\
\hline Estradiol & $<9.00$ & Pre-ovulatory peak (DO) 93-575 \\
$(\mathrm{pg} / \mathrm{mL})$ & & Luteal phase 43-214 \\
& & Menopause <58
\end{tabular}




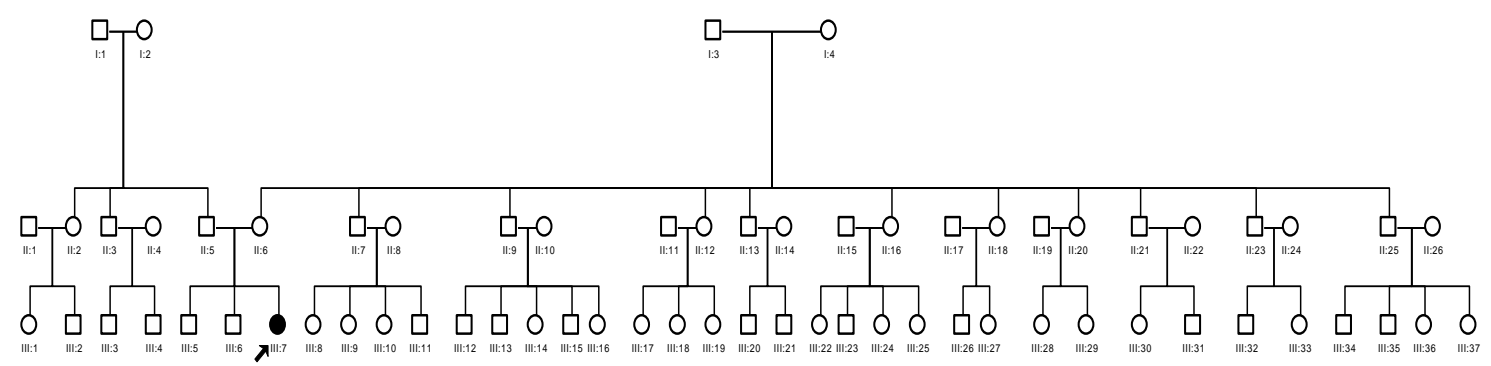

Figure 1. Pedigree of case 1: affected patients is presented by black filled circle with the arrow (III.7). Healthy members are indicated by empty circles and squares.

Ultrasonography examination showed hypoplasia uterus and ovaries. Cytogenetic analysis showed a female karyotype 46,XX without visible chromosomal anomaly.
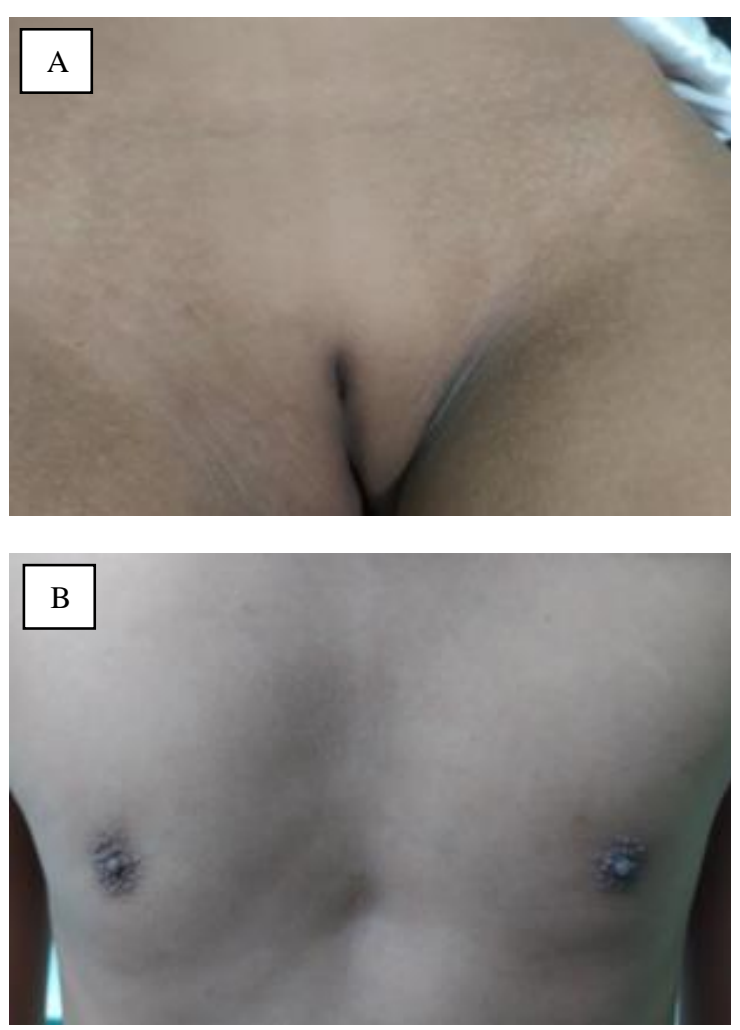

Figure 2. Physical examination: A. External genitalia is completely female with a vaginal-introital opening; B: Breast development is Tanner stage I

A diagnosis of gonadal dysgenesis was made based on clinical, laboratory and ultrasonography findings.

\section{Case 2}

A 16-year-old female (III.5) was referred to our hospital for primary amenorrhea. Her growth chart was notable for a delayed growth spurt. Her weight was 36 $\mathrm{kg}$, height $135 \mathrm{~cm}(-2 \mathrm{SD})$ and her BMI $19.6 \mathrm{~kg} / \mathrm{m}^{2}$. She had no abdominal pain, headache, visual disturbances, acne or hirsutism. There was no family history with the same condition (Figure 3). She was born full term and delivered normally by midwife. Her birth weight was 3.9 $\mathrm{Kg}$, and her birth length was $52 \mathrm{~cm}$.

Physical examination showed normal female external genitalia with introitus vagina. Her pubertal status was Tanner I for breast, pubic and axillary hair development. There was low posterior hairline, cubitus valgus and asymptomatic bilateral short fourth metatarsals (brachymetatarsia) (Figure 4).

Table 2. Laboratory evaluations of Case 2

\begin{tabular}{lll}
\hline & Result & References range \\
\hline FSH & 4.88 & Follicular phase: $3.03-8.08$ \\
& & Mid-cycle peak: $2.55-16.69$ \\
& & Luteal phase: $1.38-5.47$ \\
& Post menopause females without \\
& & HRT : 26.72-133.41 \\
\hline Estradiol & 56.03 & Follicular phase: $18-147$ \\
& & Pre-ovulatory peak (DO) 93-575 \\
& & Luteal phase 43-214 \\
& Menopause <58
\end{tabular}

Ultrasonography of abdomen showed hypoplasia uterus and ovaries. Cytogenetic analysis showed a 45,X karyotype.

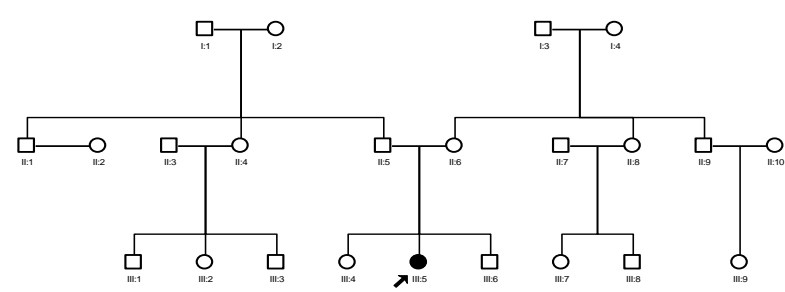

Figure 3. Pedigree of case 2. Affected patient is presented by black filled circle with the arrow (III.5). Healthy members are indicated by empty circles and squares.
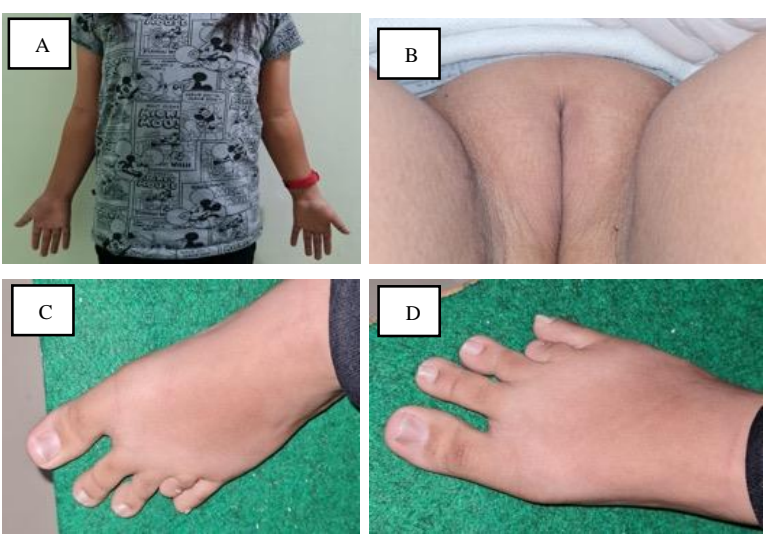

Figure 4. Physical examination A. Cubitus Valgus, B. External genitalia is completely female with a vaginalintroital opening, C and D. Bilateral Short forth metatarsals 


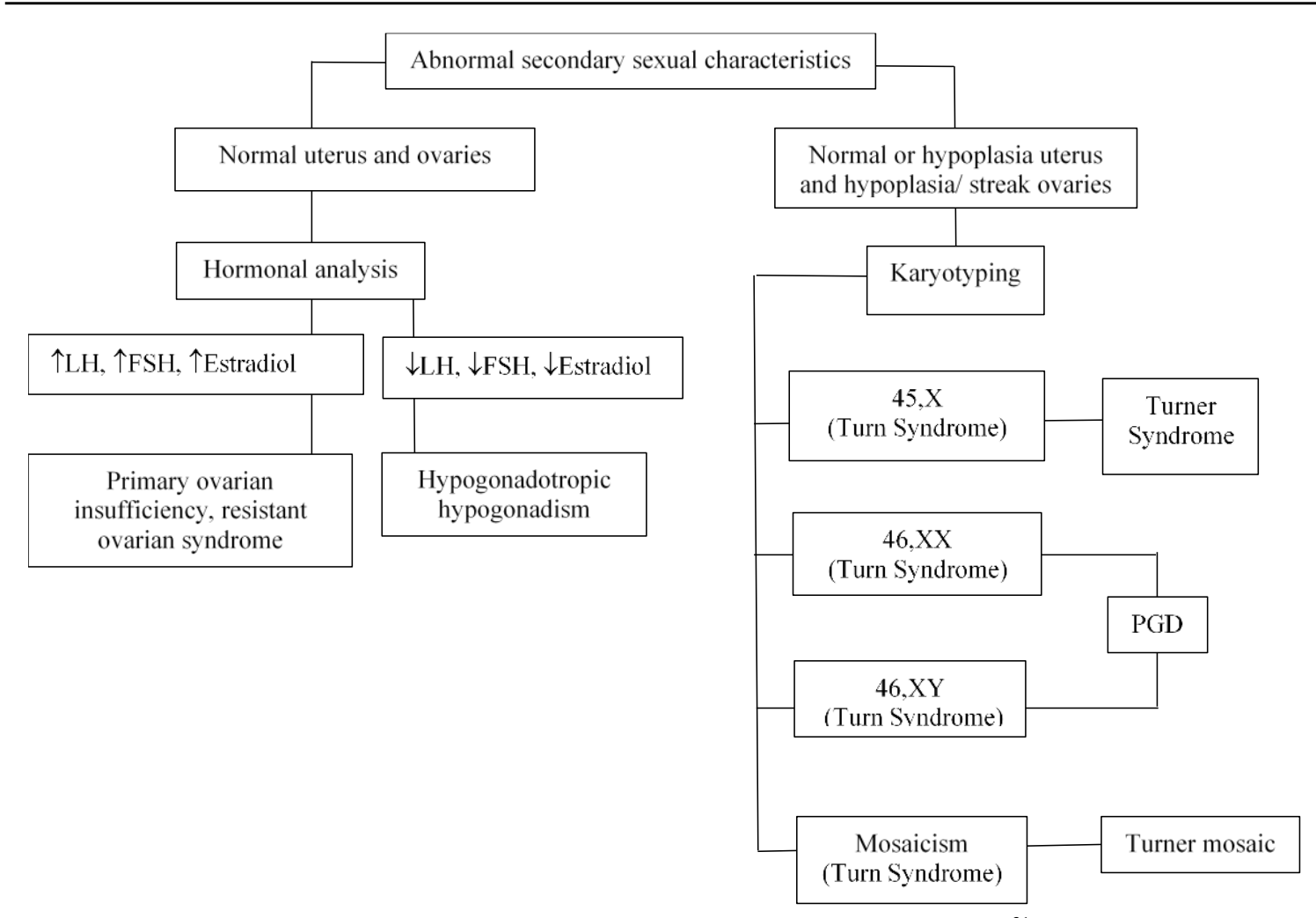

Figure 5. Flow chart of diagnostic protocol for delaved secondary sexual characteristics. ${ }^{31}$

A diagnosis of Turner Syndrome was made based on cytogenetic findings combined with the clinical, laboratory, and ultrasonography results.

\section{DISCUSSION}

Many conditions can lead to delayed puberty with primary amenorrhea. Puberty is considered delayed when there are no signs of breast development by 13 years of age in female and primary amenorrhea at 15 years of age. ${ }^{17}$ The most common etiology of primary amenorrhea are the presence of gonadal dysgenesis in $40 \%$ of cases. ${ }^{18}$ According to previous studies, primary amenorrhea due to chromosomal abnormalities was reported varied from $15.9 \%$ to $63.3 \%$ and turner syndrome either $45, \mathrm{X}$ or its mosaic form is the leading cause of primary amenorrhea. ${ }^{11}$ A comprehensive family history and physical examination and laboratory testing of affected individuals are required for diagnosis. The clinicians should inquire about the height, weight and body mass index of those with delayed puberty since they may present with short stature. ${ }^{19}$

Both of cases had the same symptoms of delayed puberty (Tanner 1 for breast, pubic hair and axillary hair) with primary amenorrhea. Evaluation of delayed puberty with primary amenorrhea begins with a complete family history and physical examination including the assessment of the external genitalia and internal female genitalia by ultrasonography as well as determination of hormonal status. This approach will identify the most common cause of delayed puberty with primary amenorrhea. ${ }^{18}$ Medical history with height and weight charts, nutritional status, medications, history and symptoms of chronic diseases also needed to evaluate if pubertal development is delayed. ${ }^{1}$ The height can be affected by delayed puberty and it is slightly below the genetic target. ${ }^{3}$
Increasing estrogen level in girls resulting in gradual breast tissue, and pubertal growth spurth. ${ }^{1}$ The two cases had different hormonal results, although both of our cases showed hypoplasia of uterus and ovaries on the ultrasonography. The first case showed low FSH and estrogen levels, while in the second case showed low FSH but normal estrogen level.

Primary ovarian insufficiency (POI) is a condition characterized by follicle depletion or dysfunction leading to impaired ovarian function which suggested by low level of FSH. ${ }^{20}$ Both of cases had low level of FSH and this is confirmed a POI. Congenital POI can be due to gonadal dysgenesis and turner syndrome or variant. ${ }^{20}$ The first case is diagnosed as gonadal dysgenesis due to absence or insufficient development of ovaries that present with delayed puberty and primary amenorrhea. Heterogeneity of genetic defects resulting in delayed puberty. The importance of defects in GnRH neuronal development and LH/FSH abnormalities due to gene mutations also control of pubertal timing. PROP1 mutations are the most common cause of pituitary hormone deficiency in humans that associated with delayed puberty. ${ }^{7}$

Morphogenesis and differentiations of Mullerian duct (MD) that plays an important role in female reproduction can also be impaired due to the effects of teratogens or genetic mutation. Defects of MD development can lead to disorders of female reproductive tract such as a dysplastic or absent vagina, cervix and uterus. Mutation has been linked in early MD genes such as L1M1, WNT4, and WNT9B can cause MRKH or related abnormalities. ${ }^{21}$ The first case of delayed puberty with primary amenorrhea was reported had family history of toxic agent and medications which was used during fetal development. Furthermore, she had a history of tuberculosis during childhood which can be linked to chronic disease. Her weight and height were $26 \mathrm{~kg} 143$ 
$\mathrm{cm}$ and her BMI showed malnutrition with $12.7 \mathrm{~kg} / \mathrm{m}^{2}$. Malnutrition has been linked with delayed puberty while direct mechanism had not been established. ${ }^{22}$ The karyotype result was $46, \mathrm{XX}$ and this confirmed a gonadal dysgenesis. Measurement of FSH, LH and estradiol will provide sufficient information to rule out organic causes of amenorrhea. ${ }^{1}$ There was no sex chromosomal aberrations were detected. Cytogenetic analysis showed 46,XX of the first case, it may be caused by mutation in genes that involved in gonadal development and differentiation.

Turner syndrome is caused by partial or complete absence of the $\mathrm{X}$ chromosome in female, with phenotypic features among affected individuals are varied. ${ }^{23}$ Common physical characteristics in Turner syndrome include; short stature, webbed neck, low posterior hair line, shield chest or nipple distance, and cubitus valgus. ${ }^{24}$ The second case did not have webbed neck, shield chest or nipple distance, and others Tuner syndrome stigmata. Physical examination of the second case were dysmorphic features such as cubitus valgus, low posterior hair lines and brachymetatarsia. The observations of this patient indicated a chromosomal aberration and therefore, a karyotype was obtained and the karyotype result was 45,X confirmed Turner syndrome. In recent study, the classical karyotype of 45 ,X was only found in $45 \%$ of patients. The phenotypic of short stature is common in all patients with Turner syndrome. $^{25}$ In this case, her weight was $36 \mathrm{~kg}$ and she had short stature (-2SD), which is a classical findings of Turner syndrome. Brachymetatarsia is a rare condition that arises from premature closure of the metatarsal epiphyseal plate, while the most common skeletal abnormality in turner syndrome is cubitus valgus, that is, the premature closure of the antebrachial long bones. ${ }^{26}$ The fourth metatarsal is the most frequently involved, females are almost exclusively affected, and it can be associated with Turner syndrome. ${ }^{27}$ There are many health conditions associated with Turner syndrome, one of those is a congenital heart defect in almost $50 \%$ of cases $^{28,29}$ and the mortality rate is increasing three times higher among patients with Turner syndrome who have congenital heart defect. ${ }^{28}$ It is important that diagnosis and treatment are important to undertake in early life Assessment to confirm the type of congenital heart disease can be done using echocardiography to performed better management and treatment. ${ }^{30}$

\section{CONCLUSION}

These cases highlight that cytogenetics can lead to an accurate diagnosis of etiology and management of delayed puberty with primary amenorrhea cases. Health care professionals should be aware that the sexual genotype of delayed puberty and primary amenorrhea cases to offer appropriate treatment.

\section{REFERENCES}

1. Seppä S, Kuiri-Hänninen T, Holopainen E, et al. MANAGEMENT OF ENDOCRINE DISEASE: Diagnosis and management of primary amenorrhea and female delayed puberty. Eur J Endocrinol 2021; 184: R225-r242. 2021/03/10. DOI: 10.1530/eje-20-1487.
2. Gruber CJ, Tschugguel W, Schneeberger C, et al. Production and actions of estrogens. The New England journal of medicine 2002; 346: 340-352. 2002/02/01. DOI: 10.1056/NEJMra000471.

3. Howard SR and Dunkel L. Delayed PubertyPhenotypic Diversity, Molecular Genetic Mechanisms, and Recent Discoveries. Endocr Rev 2019; 40: 1285-1317. 2019/06/21. DOI: 10.1210/er.2018-00248.

4. Eaves L, Silberg J, Foley D, et al. Genetic and environmental influences on the relative timing of pubertal change. Twin research : the official journal of the International Society for Twin Studies 2004; 7: 471-481. 2004/11/06. DOI: $10.1375 / 1369052042335278$.

5. Cousminer DL, Stergiakouli E, Berry DJ, et al. Genome-wide association study of sexual maturation in males and females highlights a role for body mass and menarche loci in male puberty. Human molecular genetics 2014; 23: 4452-4464. 2014/04/29. DOI: 10.1093/hmg/ddu150.

6. Supornsilchai V, Jantarat C, Nosoognoen $\mathrm{W}$, et al. Increased levels of bisphenol A (BPA) in Thai girls with precocious puberty. Journal of pediatric endocrinology \& metabolism : JPEM 2016; 29: 1233-1239. 2016/01/27. DOI: 10.1515/jpem-20150326.

7. Howard SR and Dunkel L. The Genetic Basis of Delayed Puberty. Neuroendocrinology 2018; 106: 283-291. 2017/09/20. DOI: 10.1159/000481569.

8. Varimo T, Miettinen PJ, Känsäkoski J, et al. Congenital hypogonadotropic hypogonadism, functional hypogonadotropism or constitutional delay of growth and puberty? An analysis of a large patient series from a single tertiary center. Human reproduction (Oxford, England) 2017; 32: 147-153. 2016/12/09. DOI: 10.1093/humrep/dew294.

9. Latronico AC, Brito VN and Carel JC. Causes, diagnosis, and treatment of central precocious puberty. The lancet Diabetes \& endocrinology 2016; 4: 265-274. 2016/02/08. DOI: $10.1016 / \mathrm{s} 2213-8587(15) 00380-0$.

10. García-Acero M, Moreno O, Suárez F, et al. Disorders of Sexual Development: Current Status and Progress in the Diagnostic Approach. Current urology 2020; 13: 169-178. 2020/01/31. DOI: 10.1159/000499274.

11. Soltani N, Mirzaei F and Ayatollahi H. Cytogenetic Study of Patients with Primary Amenorrhea in The Northeast of Iran. Iranian Journal of Pathology 2021; 16: 57-61.

12. Pal AK, Ambulkar PS, Sontakke BR, et al. A Study on Chromosomal Analysis of Patients with Primary Amenorrhea. Journal of human reproductive sciences 2019; 12: 29-34. 2019/04/23. DOI: 10.4103/jhrs.JHRS_125_17.

13. Current evaluation of amenorrhea. Fertility and sterility 2008; 90: S219-225. 2008/11/26. DOI: 10.1016/j.fertnstert.2008.08.038.

14. Dutta UR, Ponnala R, Pidugu VK, et al. Chromosomal Abnormalities in Amenorrhea : A Retrospective Study and Review of 637 Patients in South India. Archives of Iranian Medicine 2013; 16: 267-270. 
15. Festa A, Umano GR, Miraglia Del Giudice E, et al. Genetic Evaluation of Patients With Delayed Puberty and Congenital Hypogonadotropic Hypogonadism: Is it Worthy of Consideration? Frontiers in endocrinology 2020; 11: 253. 2020/06/09. DOI: 10.3389/fendo.2020.00253.

16. Shah VN, Ganatra PJ, Parikh R, et al. Coexistence of gonadal dysgenesis and Mayer-RokitanskyKuster-Hauser syndrome in 46, XX female: A case report and review of literature. Indian J Endocrinol Metab 2013; 17: S274-277. 2013/11/20. DOI: 10.4103/2230-8210.119605.

17. Hughes HK, Mendley S, Cooke D, et al. Case 2: Delayed Puberty in a 15 -year-old Girl. Pediatrics in review 2020; 41: 485-488. 2020/09/03. DOI: 10.1542/pir.2018-0275.

18. Ghaffari F, Keikha F and Arabipoor A. A rare case of primary amenorrhea with two etiologies, hypothalamic amenorrhea, transverse vaginal septum, and no hematocolpos. Case Rep Obstet Gynecol 2015; 2015: 989123. 2015/03/19. DOI: $10.1155 / 2015 / 989123$.

19. Klein DA, Emerick JE, Sylvester JE, et al. Disorders of Puberty: An Approach to Diagnosis and Management. American family physician 2017; 96: 590-599. 2017/11/03.

20. Klein DA and Poth MA. Amenorrhea: an approach to diagnosis and management. American family physician 2013; 87: 781-788. 2013/08/14.

21. Roly ZY, Backhouse B, Cutting A, et al. The cell biology and molecular genetics of Müllerian duct development. Wiley interdisciplinary reviews Developmental biology 2018; 7: e310. 2018/01/20. DOI: 10.1002/wdev.310.

22. Tryggestad JB and Chernausek SD. BMI changes through childhood: the impact on puberty, linear growth and hormonal regulation. Pediatric research 2020; 88: 11-13. 2020/04/17. DOI: 10.1038/s41390-020-0903-9.
23. Gravholt $\mathrm{CH}$, Viuff $\mathrm{MH}$, Brun $\mathrm{S}$, et al. Turner syndrome: mechanisms and management. Nature reviews Endocrinology 2019; 15: 601-614. 2019/06/20. DOI: 10.1038/s41574-019-0224-4.

24. Morgan T. Turner syndrome: diagnosis and management. American family physician 2007; 76: 405-410. 2007/08/22.

25. Cui X, Cui Y, Shi L, et al. A basic understanding of Turner syndrome: Incidence, complications, diagnosis, and treatment. Intractable Rare Dis Res 2018; 7: 223-228. 2018/12/19. DOI: 10.5582/irdr.2017.01056.

26. Lee YL and Wu LL. Clinical Features of Girls with Turner Syndrome in a Single Centre in Malaysia. $J$ ASEAN Fed Endocr Soc 2019; 34: 22-28. 2019/01/01. DOI: 10.15605/jafes.034.01.05.

27. Formosa N, Buttigieg M and Torpiano J. Congenital brachymetatarsia and Turner syndrome. Arch Dis Child 2016; 101: 332. 2015/11/20. DOI: 10.1136/archdischild-2015-309707.

28. Donato B and Ferreira MJ. Cardiovascular risk in Turner syndrome. Revista portuguesa de cardiologia 2018; 37: 607-621. 2018/06/06. DOI: 10.1016/j.repc.2017.08.008.

29. Dulac Y, Pienkowski C, Abadir S, et al. Cardiovascular abnormalities in Turner's syndrome: what prevention? Archives of cardiovascular diseases 2008; 101: 485-490. 2008/10/14. DOI: 10.1016/j.acvd.2008.05.007.

30. Ramírez J. Turner syndrome case presentation. Journal of Cardiology \& Current Research 2018; 11: 221-223. DOI: 10.15406/jccr.2018.11.00403.

31. GS A, KK T and Geetha S. A Clinical Study of Primary Amenorrhea. J South Asian Feder Obst Gynae 2015; 7: 158-166. 